Faculdade de FormaÇão de Professores

\title{
VERBOS INCOMPATÍVEIS COM O PROGRESSIVO ESTUDO COMPARATIVO DO INGLÊS E DO PORTUGUÊS
}

\author{
Afrânio da Silva Garcia (UERJ) \\ afraniogarcia@gmail.com
}

\section{Introdução}

O objetivo deste trabalho é apresentar, na medida do possível, os motivos que fazem com que determinados tipos de verbos sejam incompatíveis com as formas que expressam aspecto progressivo no inglês, enquanto o mesmo tipo de verbos é usado comumente no português. Pretendo também verificar a ocorrência do inverso, i.e., se existem verbos que não admitem formas progressivas no português, enquanto verbos ingleses equivalentes são compatíveis com as formas progressivas.

Para maior clareza na exposição, dividi o trabalho em quatro partes: na primeira, procurei esclarecer o que seja aspecto e suas divisões, bem como abordar as noções afins de caráter e fase; na segunda, fiz uma apresentação geral dos sistemas temporais-aspectuais do inglês e do português, suas identidades e diferenças; na terceira, algumas classificações de verbos que determinam o uso das formas progressivas ou seus significados; e na última, distingui os vários significados que as formas progressivas assumem no inglês e no português e em que se assemelham ou diferenciam.

Após a apresentação e explicação de todos esses fatores que influem sobre as formas progressivas, procurei tirar deles as conclusões mais acertadas, de acordo com meu conhecimento e experiência. Quanto à validade deste trabalho, julgo que ele será de utilidade para um melhor entendimento do uso das formas progressivas, principalmente por serem elas apenas superficialmente abordadas nas gramáticas mais consideradas do português, e pelos conceitos mais modernos, tais como aspecto, caráter e fase, nos quais se baseia para sua análise. 


\section{Aspecto}

\subsection{Definição}

Muitas línguas, entre as quais o português, fazem confusão entre as noções de tempo e aspecto verbais, principalmente devido ao hábito latino de chamar aspecto de tempo. Assim sendo, nós chamamos um mesmo tempo verbal (o passado) com dois aspectos (o perfectivo e o imperfectivo) de tempos diferentes (o Pretérito Perfeito e o Pretérito Imperfeito). Para evitarmos esse tipo de equívoco, é necessário termos uma definição mais precisa do que seja tempo, antes de começarmos a tratar do aspecto.

Tempo é uma categoria gramatical que relaciona a situação expressa por um verbo à realidade extralinguística do tempo (cronológico). Essa relação baseia-se no momento da fala, já que ele é compartilhado pelo falante e pelo ouvinte. A partir daí temos o tempo presente, que é o momento em que se fala ou qualquer período de tempo abrangendo o momento da fala; o tempo passado, que é qualquer momento ou período anterior ao momento da fala; e o tempo futuro, que é qualquer momento ou período posterior ao momento da fala. Como todos os tempos são localizados em relação ao momento da fala, nós podemos descrever tempo como uma categoria dêitica.

Aspecto, por sua vez, é uma categoria gramatical que não se relaciona a nada, a não ser à própria situação expressa pelo verbo, tanto assim que pode ser usado nas formas nominais.

Exemplos:

\section{1) Gostaria de nadar um pouco.}

\section{2) Gostaria de estar nadando numa piscina.}

Visto que aspecto não é uma categoria dêitica, nem está relacionado a algo que não seja a situação em si, vejamos em que se constitui o aspecto. De acordo com Comrie (1978, p. 3), "os aspectos são maneiras diferentes de se ver a constituição temporal interna de uma situação". A partir daí, teremos os vários aspectos, de acordo com os vários modos pelos quais uma situação pode ser vista. Lyons (1979, p. 707) destaca as seguintes noções semânticas que dizem respeito a aspecto, i.e., podem ser diferenciadas através do aspecto: estatividade, progressividade, duração, completividade, habituali- 
dade, iteração, momentaneidade ou transitoriedade, princípio ou incoatividade e terminação. Além dessas noções, Comrie ainda apresenta a noção de relevância corrente do aspecto (?) perfeito e o aspecto prospectivo (mas este pode ser uma maneira de demonstrar a noção de princípio). Veremos agora esses aspectos mais detalhadamente.

\subsection{Perfectivo $x$ imperfectivo}

A maior parte das línguas que distinguem aspecto gramaticalmente faz distinção entre perfectivo e imperfectivo, em que o aspecto perfectivo descreveria a situação como um todo único, sem dar atenção às partes que a constituem ou às várias instâncias em que a situação ocorre, enquanto que o aspecto imperfectivo referir-se-ia explicitamente à estrutura temporal interna de uma situação. Como se pode ver a constituição interna de uma situação de várias maneiras, mas só se pode ver, na maioria dos casos, a situação como um todo de uma única maneira, o perfectivo geralmente apresenta uma só forma, enquanto existem vários tipos de imperfectivo.

\subsection{Tipos de imperfectivo}

\subsubsection{Habitual x contínuo}

Enquanto muitas línguas tendem a agrupar todos os sentidos do imperfectivo debaixo de uma mesma denominação, é comum entre outras línguas fazer uma distinção entre dois sentidos básicos, ou tipos, de imperfectivo: habitual e contínuo. Assim sendo, há línguas que apresentam só uma forma que cobre todos os sentidos do imperfectivo, outras que tem uma forma para habitual e outra para contínиo, outras que só marcam o habitual ou o contínuo (geralmente através de uma de suas subdivisões, o progressivo) e há ainda aquelas, como o português, que apresentam uma forma geral ao lado de uma específica.

Habitual é o tipo de imperfectivo que exprime um hábito ou uma repetição regular e constante. Comrie (1976, p. 27) enfatiza a diferença entre habitualidade (repetição regular e constante) e iteratividade (repetição ocasional) e afirma que "a mera repetição não é 
suficiente para que se use uma forma especificamente habitual (ou, sequer, imperfectiva)".

Exemplos:

3) a. The lecturer stood up, coughed three times and said. (forma perfectiva: Simple Past)

b. O orador levantou-se, tossiu três vezes e disse. (forma perfectiva: Pretérito Perfeito)

4) a. The heavy-smoker used to cough his lungs out every morning. (forma imperfectiva habitual: used to)

b. O fumante inveterado tossia seus pulmões para fora todas as manhãs. (forma imperfectiva: Pretérito Imperfeito)

Lyons (1979, p. 716), por sua vez, chama nossa atenção para a impropriedade do termo habitual e dá como exemplo o fato de podermos dizer que "uma árvore dava frutas todo mês de outubro" ( $u$ sed to shed its fruit in October) usando a forma habitual, mas que não podemos considerar que a árvore tinha o hábito de dar frutas.

Contínuo, então, seria o tipo de aspecto imperfectivo não habitual, i.e., que não se referisse a uma repetição regular e constante de uma situação. O aspecto contínuo, no entanto, também se divide em dois tipos: progressivo e não progressivo, como veremos a seguir.

\subsubsection{Progressivo $x$ não progressivo}

A melhor definição do aspecto progressivo que eu encontrei foi a de Comrie (1978, p. 12): "Progressividade é a combinação de continuidade com não estatividade". Essa definição é muito interessante por dois motivos: primeiro, por delimitar precisamente o campo de significado coberto pelo progressivo; segundo, por delimitar o tipo de situação: estatividade, incompatível com o aspecto progressivo, o que é de muita utilidade para a elaboração deste trabalho. Mas, apesar da sua precisão, a definição de Comrie não elimina todas as dificuldades com respeito ao progressivo, pois embora o con- 
ceito de continuidade seja mais ou menos uniforme (duratividade), o conceito de estatividade é mais variável, visto que o que os falantes de uma língua consideram um verbo estativo e, portanto, incompatível com o progressivo, outra considera um verbo não estativo (como nos verbos de percepção inerte: ver, ouvir, etc. que são incompatíveis com o progressivo no inglês, mas não no português). Tentarei explicar o porquê dessas diferenças mais adiante, quando tratar dos sentidos do progressivo numa e noutra língua.

Quanto ao aspecto contínuo não progressivo, que pela definição do progressivo, continuidade com não estatividade, vem a ser o mesmo que aspecto estativo, nem mesmo Comrie não chegou a dar uma definição das circunstâncias em que ele ocorreria, nem forneceu exemplos. Somente Lyons chegou a dar um exemplo de aspecto estativo, como veremos a seguir.

\subsubsection{Outros aspectos}

O mais conhecido dos aspectos que não se enquadram na oposição anterior entre perfectivo e imperfectivo e suas divisões é o perfeito. Em primeiro lugar, é preciso deixar claro que o aspecto perfeito não implica aspecto perfectivo, tanto assim que o perfeito admite aspecto progressivo nas línguas que o possuem.

Exemplos:

5) a. He has read the book. b. Ele leu o livro. - perfectivo

6) a. He has been reading the book since yesterday.

b. Ele esteve/tem estado lendo o livro desde ontem. - progressivo

Comrie (1978, p. 52) afirma que o perfeito "é um aspecto num sentido bastante diferente dos outros aspectos abordados até agora". Essa diferença se deve ao fato de que o perfeito "não nos diz nada da situação em si, mas expressa a relação entre um estado e uma situação precedente." Mais adiante, Comrie (1978, p. 64) diz que "o perfeito é retrospectivo, já que ele estabelece uma relação entre um estado num tempo e uma situação num tempo anterior". 
Lyons (1979, p. 714-5) considera o perfeito "um aspecto estativo usado para representar o estado que ele, o perfeito, denota como sendo uma consequência da realização do processo que o verbo (em outros aspectos que não o perfeito) denota”.

A melhor definição seria então: o perfeito é um aspecto estativo e retrospectivo ao mesmo tempo, a qual cobriria todos os usos do perfeito, quer resultativo, quer continuativo.

Outro aspecto de muita importância para este trabalho é o prospectivo, que expressa a relação entre um estado e uma situação posterior. Comrie (1978, p. 64) cita como expressões de aspecto prospectivo as construções "to be going to, to be on the point of, to be about to" e dá como exemplos "The ship is about to sail; The ship is on point of sailing" (O navio está quase partindo; $\mathrm{O}$ navio está a ponto de partir) e "Bill is going to throw himself off the cliff" (Bill vai se jogar do penhasco). Voltarei ao aspecto prospectivo mais adiante.

\subsection{Caráter e fase}

Lyons (1979, p. 706) recusa o termo aktionsart pela confusão que este gera e prefere chamar de caráter aspectual ou simplesmente caráter a lexicalização de uma distinção de aspecto. Ele dá o exemplo dos verbos know (conhecer) e recognize (reconhecer), cuja única diferença é que um descreve a situação como um estado e o outro como um evento. É importante notar que, como ambos, o aspecto e o caráter, repousam sobre as mesmas distinções ontológicas, um aspecto só pode ocorrer com verbos cujo caráter seja compatível com o aspecto (por exemplo, o progressivo só pode ocorrer com verbos não estativos).

Comrie (1978, p. 103-5) e Lyons (1979, p. 717) chamam a atenção também para o que eles chamam de estados permanentes ou absolutos em oposição a estados temporários ou contingentes. Um exemplo disso é a oposição entre os verbos ser (estado permanente) e estar (estado temporário).

Lyons (1979, p. 710-2) apresenta também a noção de "fase", a qual mantenho entre aspas porque ainda não foi perfeitamente de- 
finida (Palmer, por exemplo, chama de fase ao perfeito). "Fase" é o termo para designar "uma situação em qualquer ponto de tempo (momento) dado da sua duração" (COMRIE, 1978, p. 48). Assim sendo, as situações durativas, estados e processos, têm uma diferença no fato de que os estados são homogêneos e imutáveis em todas as suas fases, enquanto os processos não são; ao mesmo tempo, eles são semelhantes pelo fato de que se dissermos que um estado ou um processo ocorreu de um tempo $t_{1}$ a um tempo $t_{2}$, estaremos dizendo também que esse estado ou esse processo ocorreram em qualquer tempo $t_{3}$ entre $t_{1}$ e $t_{2}$.

Os processos, por sua vez, dividem-se em atividades (processos atélicos) e realizações (processos télicos). Essa distinção entre situações télicas, i.e., que envolvem um objetivo a ser alcançado, e atélicas, i.e., as que não envolvem um objetivo, é de extrema importância. Veremos isso mais profundamente adiante.

\section{O sistema temporal-aspectual inglês e português}

\subsection{O sistema temporal-aspectual inglês}

Palmer (1978, p. 31-3) fez uma descrição brilhante do sistema temporal-aspectual inglês. Como para nós não interessam nem as formas de infinitivo nem as participiais, bem como as formas correspondentes para a voz passiva, eu me dei à liberdade de omitir essas formas na minha apresentação do paradigma do sistema temporalaspectual inglês. Escolhi manter o mesmo verbo e pessoa (take, $3^{\text {a }}$ p.s.), mas ordenei o paradigma em 2 colunas, uma para as formas não progressivas e outra para as formas progressivas, já que o trabalho é sobre aspecto progressivo. O paradigma passa a ser então como segue:

$\begin{array}{ll}\text { Formas simples } & \text { Formas progressivas } \\ \text { 1) take } & \text { is taking } \\ \text { 2) took } & \text { was taking } \\ \text { 3) has taken } & \text { has been taking } \\ \text { 4) had taken } & \text { had been taking }\end{array}$

Palmer não coloca no seu paradigma nem a construção de passado habitual used to + infinitivo nem as formas de futuro + infi- 
nitivo ou would + infinitivo, assim como as construções com be going to + infinitivo, e os derivados dessas quatro construções. Desse modo, o paradigma fica reduzido a:

1) uma forma de presente simples para situações habituais ou contínuas e uma forma progressiva;

2) uma forma perfectiva de passado e uma forma progressiva, também usada como imperfectiva não habitual (em oposição ao imperfectivo habitual used to);

3) uma forma simples de perfeito (continuativo ou resultativo) com uma forma progressiva (preferencialmente continuativo);

4) uma forma simples do passado perfeito (continuativo ou resultativo) com uma forma progressiva (também preferencialmente continuativo).

É importante assinalar que para cada uma dessas formas existe uma forma passiva, mas que só existem três formas participiais (taking, having taken e having been taking) e quatro de infinitivo (uma para cada aspecto e uma para perfeito progressivo: to take, to have taken, to be taking e to have been taking).

\subsection{O sistema temporal-aspectual português}

Seguindo o esquema apresentado por Palmer, só que adaptando-o para o português, tentarei montar um paradigma que torne claro para o leitor o sistema temporal-aspectual do português. Seguirei o mesmo procedimento de omitir a passiva e as formas de infinitivo (o português não tem formas participiais cambiáveis com o infinitivo, como o inglês).

Em primeiro lugar, gostaria de explicar uma diferença fundamental entre o aspecto progressivo como é gramaticalizado no inglês e no português, já que o inglês só tem uma forma (dividida em várias, de acordo com o tempo ou aspecto a que está relacionada) de expressar o progressivo, enquanto o português tem duas formas de expressar o progressivo (divididas em outras também): estar + gerúndio e estar + preposição $a+$ infinitivo, sendo que a primeira (es- 
tar + gerúndio) é mais usada no Brasil, enquanto a segunda (estar a + infinitivo) é mais usada em Portugal.

Exemplos:

\section{7) João está cantando.}

\section{8) João está a cantar.}

É importante notar que embora uma forma seja mais usada aqui e outra lá, ambas são usadas e entendidas nos dois lugares.

Resolvi manter no paradigma que vou apresentar o mesmo verbo e pessoa do de Palmer (levar, $3^{\mathrm{a}}$ pessoa sing.), mas como talvez seja um trabalho pioneiro (pelo menos, nos livros em que pesquisei, o progressivo era abordado de uma maneira bem superficial, exceção feita a Celso Cunha) resolvi nomear cada forma, tentando ser o mais explícito possível. O paradigma básico do verbo no português fica assim então:

Formas simples

Formas progressivas

Presente:

leva

está levando/a levar

Pretéritos:

Perfeito: levou estive levando/a levar

Imperfeito: levava estava levando/a levar

Perfeito composto:

tem levado tem estado levando/a levar

Mais-que-perfeito:

levara

estivera levando/a levar

Mais-que-perfeito

composto:

tinha levado

tinha estado levando/a levar

Futuros:

Presente: levarei estarei levando/a levar

Pretérito: levaria estaria levando/ a levar

De acordo com o paradigma, temos os seguintes tempos verbais no português: 
a) Presente - com uma forma simples para situações habituais, estativas, contínuas e momentâneas (quando não repetidas), e uma forma progressiva para situações temporárias ou progressivas;

b) Pretérito perfeito simples - para situações perfectivas, com uma forma progressiva para situações passadas durativas temporalmente limitadas;

c) Pretérito imperfeito simples - para situações imperfectivas, com uma forma progressiva para ações passadas durativas temporalmente indefinidas;

d) Pretérito perfeito composto - o nosso perfeito presente, com uma variedade de usos imensa, com uma forma progressiva continuativa;

e) Pretérito mais-que-perfeito simples - com uma forma progressiva durativa (ambos atualmente caindo em desuso, substituídos pelo mais-que-perfeito composto);

f) Pretérito mais-que-perfeito composto simples - para passado distante, passado-do-passado e passado perfeito, com uma forma progressiva continuativa (esses são, tirando os usos de passado perfeito, os usos também do mais-que-perfeito simples);

g) Futuro do presente simples - para situações futuras, com uma forma progressiva para situações futuras durativas;

h) Futuro do pretérito simples, para situações futuras em relação a um tempo passado ou para situações hipotéticas, com uma forma progressiva para as mesmas situações quando durativas.

Além das formas do paradigma, o verbo português teria ainda as formas da voz passiva (como já foi dito), as formas do subjuntivo (sendo a diferença mais importante a do imperfeito simples em oposição a um perfeito composto: levasse $\mathrm{x}$ tenha levado), as formas compostas, chamadas de perfeitas, do futuro do presente (terá levado) e do pretérito (teria levado, de uso raro), bem como as formas compostas com o verbo haver e as infinitivas, que deixaremos de abordar por necessidade de concisão. 


\subsection{Comparação entre os dois sistemas}

A principal diferença, e também a mais marcante, entre o sistema temporal-aspectual inglês e português, é a existência de uma oposição entre imperfectivo e perfectivo (pretérito imperfeito e perfeito) no português ao lado da oposição entre progressivo e não progressivo.

Outra diferença importante é a existência de um aspecto perfeito no inglês, enquanto que nossas formas similares têm menos valor de aspecto e mais de tempo. Assim, para o Present Perfect nos teríamos um passado-no-presente (tenho levado); para o Past Perfect nos teríamos um passado-no-passado (tinha levado) e para o Future Perfect nos teríamos um passado-no-futuro (terei levado), além de um passado-no-futuro-do-passado (teria levado) para a forma would have taken.

Teríamos ainda, como diferenças, a existência de um subjuntivo no português com suas formas específicas, e as formas específicas de tempos futuros no português, o que não ocorre no inglês, enquanto que o inglês tem formas participiais de infinitivo e uma forma específica de aspecto habitual: used to, que o português não possui.

\section{Classificação dos verbos}

\subsection{Classificação quanto ao caráter}

A principal classificação de um verbo é a que se faz com relação ao caráter, já que ele determinará os aspectos compatíveis com o verbo e também porque essa classificação é de tal modo abrangente que engloba todos os verbos, sem exceção.

Os verbos podem ser de dois tipos, de acordo com o caráter. Lyons (1979, p. 706) os classifica como verbos de evento e verbos de estado, enquanto Comrie (1978, p. 48) os classifica em verbos de estado e verbos de situação dinâmica. Como os termos evento e estado não têm o mesmo sentido em português que em inglês, assim como o termo dinâmico faz lembrar movimento e muitas situações dinâmicas não envolvem movimento, resolvi criar uma nova denominação, que 
não desse lugar a dúvidas. Assim sendo, os verbos podem ser divididos em dois tipos em relação ao caráter: eventivos e estativos.

Eventivos, do sentido mais amplo da palavra evento: acontecimento, ocorrência, indica um verbo que traduz a ocorrência de uma modificação qualquer, seja no sujeito, seja no objeto. Mesmo a modificação de um estado para outro, como nos verbos incoativos (envelhecer etc.), caracteriza um verbo como eventivo.

Estativos, derivado de estado, indica um verbo denotativo de uma situação em que não ocorre qualquer modificação quer no sujeito, quer no objeto.

Uma classificação que também tem a ver com caráter, já que ela distingue uma diferença aspectual de temporariedade, embora nem Lyons (1979, p. 717) nem Comrie (1978, p. 103-5) a considerem uma diferença em termos de caráter, apesar de a considerarem aspectual, é a que distingue os verbos estativos em temporários ou contingentes e absolutos ou permanentes, muito bem demonstrada no português pelos verbos estar (temporário) e ser (permanente).

\subsection{Classificação quanto à fase}

Os verbos são classificados de acordo com a fase em quatro tipos. Como o fato de um verbo ser télico (envolver um objetivo) ou atélico (não envolver um objetivo), bem como o fato de ser momentâneo ou durativo, influem decisivamente na classificação de um verbo quanto à fase, usarei a nomenclatura de Zydatiss (1978, p. 341-361), por achá-la mais clara e precisa.

A classificação dos verbos de acordo com a fase fica então:

1) Verbos estativos: atélicos, durativos e homogêneos;

2) Verbos de atividade: atélicos e eventivos;

3) Verbos de realização (accomplishments): télicos, durativos e eventivos;

4) Verbos de realização instantânea (achievements ou bordercrossings): télicos, momentâneos e eventivos. 
Os verbos de atividade podem ser durativos ou momentâneos. Já os verbos de realização instantânea podem ser tornados em verbos durativos pelo uso do progressivo. Como exemplos dos tipos de verbos, teríamos:

1) Verbos estativos: ser, estar;

2) Verbos de atividade: chutar, piscar (momentâneos); correr, trabalhar (durativos);

3) Verbos de realização: construir, afogar;

4) Verbos de realização instantânea: achar, reconhecer, morrer.

\subsection{Classificação quanto ao papel agente e outras}

Nós podemos classificar os verbos a partir do papel do agente: quando o sujeito é agente do verbo, nós temos um verbo agentivo, quando não, temos um verbo não agentivo. Essa distinção é fundamental para o uso do progressivo no inglês, já que só os verbos de percepção agentivos aceitam progressivo. Outra distinção de importância para esse trabalho é a que existe entre verbos estativos qualificativos (que expressam uma qualidade ou um estado através de um adjetivo, substantivo ou advérbio de modo) e verbos estativos locativos (que expressam a localização do sujeito num determinado lugar).

Exemplos:

9) Eu vejo você. (na maioria das situações, constitui um verbo de percepção agentivo)

10)Eu olho para você. (verbo de percepção não agentivo)

11)Eu estou bem. (verbo estativo qualificativo)

12)Eu estou aqui. (verbo estativo locativo) 


\subsection{Classificação geral dos verbos}

Somando-se todas as classificações até agora apresentadas, chegamos a uma classificação bastante completa dos tipos e subtipos de verbos existentes, como veremos agora:

Classificação geral dos verbos:

\begin{tabular}{|l|l|l|}
\hline \multirow{2}{*}{ 1) Estativos: } & \multirow{2}{*}{ Permanentes: } & Qualificativos: ser \\
\cline { 2 - 3 } & \multirow{2}{*}{ Temporários: } & Locativos: haver, existir \\
\cline { 3 - 3 } & & Qualificativos: parecer \\
\hline \multirow{2}{*}{ 2) Eventivos: } & \multirow{2}{*}{ Atélicos: } & Atividades durativas - correr \\
\cline { 2 - 3 } & \multirow{2}{*}{ Télicos: } & Atividades momentâneas - chutar \\
\cline { 3 - 3 } & & Realizações durativas - construir \\
\cline { 3 - 3 } & & Realizações momentâneas - chegar, morrer \\
\hline
\end{tabular}

Além desses critérios, temos o de verbo agentivo, mas como quase sempre um verbo estativo passa a ser verbo de atividade quando agentivo e para os verbos télicos essa distinção não é importante, eu a coloquei separadamente.

\section{Significados do progressivo no inglês e no português}

A partir da definição de aspecto progressivo: continuidade com não estatividade, muitos dos sentidos que tradicionalmente se atribui ao progressivo se explicam: se considerarmos uma situação como contínua, mas não estativa, essa situação será alongada ou $d u$ rativa com verbos de atividade não durativos; terá duração limitada com verbos durativos; indicará ação incompleta com verbos de realização e indicará repetição esporádica com verbos pontuais ou instantâneos.

Além disso, o progressivo desenvolverá certos sentidos de acordo com o tempo ou aspecto ao qual estiver modificando. Assim sendo, o Presente Progressivo no inglês denota uma realidade fatual, contra uma realidade virtual do Presente Simples.

Exemplos:

13)a. He is taking the bus. 
b. Ele está pegando o ônibus.(a situação está realmente acontecendo)

14)a. He takes the bus everyday.

b. Ele toma o ônibus todos os dias. (pode ser que ele não pegue o ônibus hoje)

Com o Passado, o Progressivo inglês é simplesmente durativo; já com o Perfeito, o Progressivo inglês implica geralmente uma leitura continuativa.

Exemplos:

15)a. He has played football.

b. Ele jogou (ou esteve jogando) futebol.

16)a. He has been playing football.

b. Ele esteve jogando futebol.

Além desses sentidos progressivos do Progressivo inglês, Comrie (1978, p. 31-8) cita o desenvolvimento de um novo uso do Progressivo inglês, para indicar situação inesperada ou contrária ao habitual, conforme Lyons teria dito (embora Comrie não cite onde).

Exemplos:

17)a. I'm seeing pink elephants.

b. Eu estou vendo elefantes cor-de-rosa. (eu normalmente não vejo elefantes cor-de-rosa)

18)a. Fred is being silly.

b. Ele está sendo tolo. (ele não é tolo, normalmente)

O Progressivo no português, por sua vez, tem os seguintes significados, de acordo com o tempo verbal ao qual está relacionado:

1) Presente - indica uma situação fatual (que está realmente acontecendo);

2) Pretérito imperfeito - indica uma situação passada simultânea a outra; 
3) Pretérito perfeito - indica uma situação durativa por um período limitado, ou perfeito continuativo, que se estende até o presente;

4) Pretérito perfeito composto - perfeito continuativo, que se estende até o presente ou depois;

5) Futuro - indica uma situação futura simultânea a outra.

Os demais tempos verbais, quando usados no Progressivo, ou serão simplesmente durativos, ou serão tempos verbais derivados dos que foram expostos acima, com as mesmas funções.

Um uso especial do Progressivo no português ocorre em associação com aspecto prospectivo, para indicar iminência da situação, geralmente com verbos locativos eventivos.

Exemplos:

19)Eu vou saindo. (eu ainda estou num determinado local, mas pretendo sair num período muito breve)

Resumindo os usos das formas progressivas no inglês e no português, temos:

Inglês:

Sentido básico: progressividade

Outros: situação inesperada; estado contingente

Português:

Sentidos básicos: progressividade e situação fatual

Outros: situação inesperada; estado contingente e aspecto prospectivo.

\section{Conclusã̃o}

Como vimos, muitos são os fatores que fazem com que um verbo seja compatível ou não com o progressivo. Teoricamente, um verbo seria compativel com o progressivo quando fosse eventivo e seria incompatível quando fosse estativo, mas as coisas não são tão simples. 
Um verbo estativo deixa de ser considerado como tal e passa a ser considerado eventivo quando agentivo; o melhor exemplo disso é a clássica diferença entre os verbos de percepção ou de estados mentais ou sentimentos, que são incompatíveis com o progressivo no inglês e compatíveis com o progressivo no português, devido ao fato de serem não agentivos no inglês e agentivos no português.

Exemplos:

20)a. I see/can see it now.

b. Eu estou vendo isso agora.

21)a. I love you now!.

b. Eu estou te amando agora.

Outro fator que pode tornar um verbo estativo em eventivo ocorre quando ele indica um estado considerado variável (em intensidade ou qualquer outra característica).

Exemplo:

22)a. I'm suffering.

b. Eu estou sofrendo. (porque meu sofrimento não é sempre igual)

Quando um verbo estativo passa a expressar um sentido secundário, ele passa a ser compatível com o progressivo, mesmo que seja um verbo de estado de ser (o tipo mais incompatível com o progressivo).

Exemplos:

23)a. He is being rude.

b. Ele está sendo rude.

24)a. He's having a headache.

b. Ele está tendo uma dor de cabeça.

No português, praticamente qualquer verbo pode ser usado no progressivo, sempre que queremos expressar uma situação fatual (que está realmente acontecendo). 
Exemplo:

25)Ela era muito pobre e não tinha quase nada, mas, depois que casou com um homem rico, está tendo tudo que sempre quis.

Outra leitura do progressivo empregado para designar situação fatual é a de capacidade, possibilidade.

Exemplo:

26)Estou te vendo pelo buraco da fechadura. (posso te ver pelo buraco da fechadura)

Os únicos verbos marcadamente incompatíveis com o progressivo no português são os verbos estativos locativos, como ficar (locativo), continuar, etc., mas mesmo eles admitem forma progressiva para expressar aspecto prospectivo.

Exemplos:

\section{7) Eu vou ficando mais um pouco.}

\section{8) Eu vou continuando por aqui.}

A conclusão final a que se chega é:

1) que determinados verbos serão incompatíveis com o progressivo no inglês e compatíveis com o progressivo no português, devido ao fato de serem não agentivos no inglês e agentivos no português;

2) que mesmo verbos não agentivos podem tomar formas progressivas para expressar situação fatual;

3) que mesmo os verbos estativos locativos podem tomar formas progressivas para expressar aspecto prospectivo no português;

4) que o único verbo que nunca pode ser usado na forma progressiva no português é o verbo estar, cuja função privativa é expressar aspecto progressivo, o que tornaria extremamente redundante seu uso numa forma progressiva. 


\section{REFERÊNCIAS BIBLIOGRÁFICAS}

BECHARA, Evanildo. Moderna gramática portuguesa. 27. ed. São Paulo: Cia. Ed. Nacional, 1982.

CÂMARA JR., J. Matoso. Princípios de linguística geral. 5. ed. Rio de Janeiro: Padrão, 1977.

. História e estrutura da língua portuguesa. 3. ed. Rio de Janeiro: Padrão, 1977.

CARDOSO, Wilton \& CUNHA, Ce1so. Estilística e gramática histórica. Rio de Janeiro: Tempo Brasileiro, 1978.

CELCE-MURCIA, Marianne. Understanding and teaching the English tense-aspect system. English Teaching Forum, 15 (4), p. 2-11, 1977.

CUNHA, Celso. Gramática da língua portuguesa. 7. ed. Rio de Janeiro : FENAME, 1980.

COMRIE, Bernard. Aspect. 2. ed. cor. Cambridge: Cambridge University Press, 1978.

KALUZA, Henryk G. Systemic definition of the present, present perfect and preterit tenses. English Teaching Forum, 15 (3), p. 15$18,1977$.

LEECH, Geoffrey N. Meaning and the English verb. 8. ed. London: Longman, 1979.

LEECH, Geoffrey \& SVARTVIK; Jan. A communicative Grammar of English. London: Longman, 1975.

LIMA, C. H. da Rocha. Gramática normativa da língua portuguesa. 22. ed. Rio de Janeiro: José Olympio, 1982.

LYONS, John. Semantics. 3. ed. Cambridge: Cambridge University Press, 1979. 2 v.

PALMER, F. R. The English verb. 4. ed. London: Longman, 1974.

ZYDATISS, Wolfgang. Continuative and resultativo perfects in English? Lingua, 44, p. 334-362, 1978. 